\section{Down to development}

\author{
Michael Akam
}

From Gene to Animal: An Introduction to the Molecular Biology of Animal Development. By David De Pomerai. Cambridge University Press:1985. Pp.293. Hbk £25, $\$ 44.50 ; p b k £ 8.95, \$ 14.95$.

A sHORT text on the molecular biology of development must be a masterpiece of selection. Ideally, such a work would define questions in the language of embryology, and answer them in the language of molecular biology. We would like to know what molecules constitute maternal information, how interactions between these and the zygote genome generate more complex patterns, what description of cell types and morphology is appropriate to match the internal molecular logic, and how the differentiation of each particular cell type is executed through hierarchies or networks of control. Although such a work cannot yet be written, we might hope that a textbook for today's undergraduates would at least be able to set the scene, show where real progress has been made and, above all, convey the promise of the near future.

From Gene to Animal does not wholly succeed in meeting this agenda, in part because of the way that the book is organized. De Pomerai separates an elementary but extensive discussion of eukaryote molecular biology (the first half of the book) from a consideration of the molecular strategies of development which are condensed into one central chapter. As a result the significance of molecular mechanisms for developmental regulation sometimes slips between the cross references.

When molecular techniques are applied to the study of development, the first questions to be answered may well be the last things a student needs to know (the physical map of a gene is not always its most pertinent characteristic). De Pomerai does not go far enough to redress this bias. Much of the detail which he includes does little to illuminate the mechanism of development; the organization of histone and TRNA gene families tells us more about genome evolution than developmental regulation. Elsewhere five pages on nucleosomes could have been condensed to one longish paragraph without losing the main points.

The final three chapters are devoted to case studies. Like the rest of the book they are well written and nicely presented. They contain much useful information, and most of it is accurate, so far as I can see. But the accounts of erythroid differentiation and of the oviduct epitomize, unconsciously, the shortcomings of much molecular developmental biology. short introductory section in each chapter presents a classical, almost histological description of developmental events. The story then jumps to molecular details of terminal gene expression. In between lie many of the salient problems of development, but apart from passing reference to hormonal effects these are not considered. It would have been nice to read at least some discussion of how cellular events in erythropoesis can be investigated, for example by the use of erythropoetic cell lines.

The final chapter covers insect development; unfortunately, it was written at just the wrong time. Now, I would choose insects (more precisely, Drosophila) to illustrate a number of key topics. One would be the significance of germ-line transformation for studies of gene control elements, and for the manipulation of development by the engineered expression of regulatory genes. And while Pelement-mediated gene transfer does receive mention, it is only in the extraordinary context of chromosome puffing. This passing reference will hardly guide a student's perception of the field, and can only be explained by its hurried insertion into a near-final text.

Similar considerations no doubt excuse the short shrift given to recent demonstration of patterned gene expression in the

\section{Green revolution}

\section{Donald Boulter}

Principles of Plant Biotechnology: An Introduction to Genetic Engineering in Plants. By S.H. Mantell, J.A. Matthews and R.A. McKee. Blackwell Scientific: 1985. Pp. 269. Pbk £10.80, \$19.95.

Progress in plant genetic engineering and in development of the potential applications has been faster than was anticipated. In these circumstances it is clearly difficult to write an account of the subject suitable for undergraduates because it is the latest advances which are of most interest. In the event, this book is good on the fundamentals of plant molecular biology but this aspect has been overemphasized at the expense of the biotechnology. Moreover, the subtitle, An Introduction to Genetic Engineering in Plants, is confusing because many other areas of plant biotechnology are covered.

This is a somewhat bland account of an exciting field. The authors have been too equivocal in dealing with their subject matter, so that in parts they have been rather long-winded. The book is also too academic, no doubt reflecting the authors' experience, and often lacks critical assessment of the likely practical outcome or potential economic development of plant

\section{IMAGE \\ UNAVAILABLE FOR COPYRIGHT REASONS}

The "late pretzel" stage of embryogenesis in the nematode Caenorhabditis elegans. The picture is taken from Genetic Analysis of Animal Development, by Adam S. Wilkins, published by Wiley. Price is $\$ 69.95$, $£ 71.55$.

Drosophila blastoderm, although these results establish for the first time a link between molecular biology and pattern formation. When this text is revised, the insect chapter at least will require complete reorganization. And that will be a measure of progress.

Michael Akam is a Medical Research Counci Senior Fellow in the Department of Genetics, University of Cambridge, Downing Street, Cambridge CB2 3EH, UK.

biotechnology; for example, in the chapter on crop breeding, the section on the development of nitrogen-fixing cultivars in non-leguminous crops fails to address the whole area of the possible environmental impact of the release of genetically engineered organisms in relation to the principles and concepts of population biology and microbial ecology. Other topics inadequately dealt with include ice nucleation bacteria, herbicide resistant plants, and pest and disease resistance.

The book covers the whole field of plant biotechnology and contains basic information on genes, genetic engineering, tissue culture, cryopreservation, crop improvement by somaclonal variation and genetic engineering, plant-derived biomass and industrial plant products. The authors have read widely, and with the reservations made earlier most of the relevant information is included with relatively few points on which I would disagree. Unavoidably, however, some of the information is now out of date.

For all its failings, this book is a good attempt to cover a difficult topic. The readership at which it is aimed, undergraduates and scientists in related fields, will find it a helpful guide to what is going on in plant biotechnology, especially on the molecular biological side of things.

Donald Boulter is Professor in the Department of Botany, University of Durham, Durham DH1 $3 L E, U K$. 